\title{
Chaves para identificação dos gêneros de Elmidae (Coleoptera) ocorrentes no Estado do Rio de Janeiro, Brasil
}

\author{
Maria Inês Silva Passos ${ }^{1,2}$, Jorge Luiz Nessimian ${ }^{1} \&$ Nelson Ferreira Junior ${ }^{1}$
}

\begin{abstract}
${ }^{1}$ Departamento de Zoologia, Instituto de Biologia, Universidade Federal do Rio de Janeiro. Caixa Postal 68044, $21944-970$ Rio de Janeiro-RJ, Brasil.

${ }^{2}$ Programa de Pós-Graduação em Zoologia, Museu Nacional, Universidade Federal do Rio de Janeiro. mines@biologia.ufrj.br
\end{abstract}

\begin{abstract}
Identification keys to genera of Elmidae (Coleoptera) from Rio de Janeiro state, Brazil. Illustrated keys for identification of larvae and adult of elmid genera from Rio de Janeiro state are presented. Brief morphological characterization for larval and adult forms for each genus are presented.

KEYWORDS. Adults; Atlantic Forest; morphology; taxonomy; larvae.

RESUMO. Chaves de identificação para os gêneros de Elmidae (Coleoptera) ocorrentes no Estado do Rio de Janeiro, Brasil. Chaves ilustradas para identificação de larvas e adultos dos gêneros de Elmidae (Coleoptera) ocorrentes no Estado do Rio de Janeiro e localidades vizinhas são apresentadas. Para cada gênero, foram feitas breves caracterizações morfológicas das formas larvais e adultas.
\end{abstract}

PALAVRAS CHAVE. Elmidae; Adultos; Mata Atlântica; morfologia; taxonomia; larvas.

A família Elmidae Curtis, 1830 tem distribuição cosmopolita e inclui aproximadamente 1200 espécies, com cerca de 350 ocorrendo na Região Neotropical (Brown 1981; Spangler 1981). Habitantes, em sua grande maioria, de córregos e rios, os Elmidae possuem um ciclo de vida muito variável, de três a oito estádios larvais, levando de alguns meses a anos para completar seu desenvolvimento (Brown 1987; White \& Briham 1996). Esporadicamente, suas formas adultas deixam a água para dispersar através de vôos rápidos.

Provavelmente, devido ao tamanho pequeno e ao ambiente em que vivem, ainda há pouco conhecimento acerca dos Elmidae (Bachmann 1977). Os catálogos de Blackwelder (1944) e Junk \& Schenkling $(1910,1914)$ têm sido muito úteis devido à extensa bibliografia apresentada. Como importante contribuição, Brown (1981) reuniu dados sobre a distribuição de toda a fauna conhecida dos Elmidae. Para a fauna Neotropical, e principalmente para o Brasil, poucos estudos foram realizados sobre os mesmos, sendo Hinton (1936; 1937a, b, c; 1940a, b, c, d; 1945a, b; 1946a, b; 1951; 1970; 1972a, b, c; 1973a, b) o autor que mais contribuiu.

As referências sobre Elmidae de maior relevância para a América do Sul são: Hinton (op. cit.), Perkins \& Steiner (1981) e Spangler $(1980 ; 1981)$. Apesar dessas contribuições, provavelmente, ainda não conhecemos um grande número de espécies e não dispomos de informações importantes sobre sua posição na dinâmica dos rios. Devido à falta de chaves próprias, referentes aos Elmidae da América do Sul, a revisão para as espécies mexicanas de Hinton (1940) e o manual de identificação dos besouros Dryopoidea dos Estados Unidos da América de Brown (1972) são pontos de partida importantes por incluírem diversos gêneros presentes na América do Sul.

$\mathrm{Na}$ América do Sul, atualmente, são conhecidos 38 gêneros e cerca de 250 espécies (Manzo 2005). Com base nos trabalhos de Brown (1981), Hinton (1936; 1937a, b, c; 1940a, b, c, d; 1945a, b; 1946a, b; 1951; 1970; 1972a, b, c; 1973a, b), Passos \& Felix (2004a, b), Perkins \& Steiner (1981), Santiago-Fragoso \& Spangler (1989) e Spangler (1980; 1981; 1989; 1990), foram registrados 22 gêneros e 155 espécies no Brasil. As duas subfamílias existentes, Larainae LeConte, 1861 e Elminae Curtis, 1830, estão representadas respectivamente, por três gêneros e cinco espécies e 19 gêneros e 150 espécies. Os gêneros registrados até o momento são: Austrolimnius Carter \& Zeck, 1929; Cylloepus Erichson, 1847; Gyrelmis Hinton, 1940; Heterelmis Sharp, 1882; Hexacylloepus Hinton, 1940; Hexanchorus Sharp, 1882; Hintonelmis Spangler, 1966; Macrelmis Motschulsky 1859; Microcylloepus Hinton, 1935; Neoelmis Musgrave, 1935; Neolimnius Hinton, 1939; Phanoceroides Hinton, 1939; Phanocerus Sharp, 1882; Pilielmis, Hinton, 1971; Potamophilops Grouvelle, 1896; Promoresia Sanderson, 1954; Oolimnius Hinton, 1939; Stegoelmis Hinton, 1939; Stenhelmoides Grouvelle, 1908; Tolmerelmis Hinton, 1972; Tyletelmis Hinton, 1972 e Xenelmis Hinton, 1936.

O presente trabalho tem por objetivo apresentar uma chave ilustrada para identificação dos 16 gêneros de Elmidae ocorrentes no Estado do Rio de Janeiro (larvas e adultos).

\section{MATERIALE MÉTODOS}

Os espécimes utilizados para confecção da chave são provenientes de coletas realizadas em diversas localidades do Estado do Rio de Janeiro, entre 1990 e 2005, pertencentes à Coleção Entomológica do Departamento de Zoologia, Instituto de Biologia, Universidade Federal do Rio de Janeiro (DZRJ). 
Para a determinação de adultos, as características importantes são (Fig. 1): forma e disposição das cerdas; presença e distribuição de tomento (uma densa cobertura de cerdas finas geralmente douradas, formando escovas conspícuas nas tíbias ou revestindo a superfície de vários escleritos do corpo, funcionando como plastrão); número de segmentos e forma das antenas; presença de dentes apicais nas mandíbulas; número de segmentos nos palpos maxilares; comprimento relativo do mento; forma do submento; número de carenas no pronoto; presença de impressões longitudinais e/ou transversais no pronoto; presença de estrias acessórias e de carenas nos élitros; tamanho e forma do processo prosternal; presença de lobos no quarto e quinto segmentos abdominais; presença de dentes nas garras tarsais. As características usadas para a identificação das larvas são (Fig. 2): forma do corpo; presença de dente frontal na superfície dorsal da cabeça; tamanho relativo dos segmentos da antena; presença do processo prosternal; número de pleuritos no pro-, meso- e metatórax; presença de sutura procoxal; número de pleuritos ao longo do abdômen; presença de espiráculos ao longo do abdômen; forma, comprimento e presença de carenas no último segmento abdominal. As características foram baseadas nos trabalhos de Hinton (1940), Bertrand (1977), Brown (1973, 1972, 1971, 1970), Manzo (2005), Spangler \& Perkins (1989) e Spangler \& Santiago-Fragoso (1992). Os desenhos foram preparados com o auxilio de uma câmara clara acoplada a um microscópio estereoscópico.

Chaves para identificação dos gêneros de Elmidae (Coleoptera) ocorrentes no Estado do Rio de Janeiro

Para alguns gêneros foram encontrados somente adultos ou larvas. Neste caso, apenas o estágio encontrado foi representado na chave. Algumas larvas não foram identificadas por não poderem ser associadas a formas adultas, sendo incluídas na chave como gêneros não identificados. Como ainda é incipiente o conhecimento acerca da família no Brasil, certamente novos táxons deverão ser descritos e novos registros realizados.

\section{ADULTOS}

1. Antenas clavadas (Fig. 11a), nunca pectinadas ou flabeladas; pernas cobertas com cerdas, sem tomento; coxas anteriores transversais (Fig. 7c); trocantino visível (Larainae)

Antenas filiformes (Fig. 3a); tíbias com tomento (Fig. 3a); coxas anteriores arredondadas (Fig. 4b); trocantino não visível (Elminae).

2. Pronoto com uma forte impressão transversal atingindo as margens laterais (Figs. 7a, c) ................ Hexanchorus

Pronoto com impressões laterais, estendendo-se medianamente e posteriormente, podendo ser contínuas à impressão formada por um sulco longitudinal (Fig. 11a) Phanocerus
3. Élitro com curta estria acessória na base, entre as primeira e segunda estrias (Fig. 8a) Macrelmis

Élitro sem tal estria acessória ... 4

4. Epipleura com uma ou duas fileiras de grânulos (Fig. 3c) Austrolimnius

Epipleura sem fileiras de grânulos ... 5

5. Pronoto freqüentemente com uma impressão transversal completa ou em forma de $\mathrm{U}$, ocupando ou se iniciando nos $2 / 5$ anteriores (Fig. 9a, 10a) .................................... 6

Pronoto ocasionalmente com ou sem impressão transversal; se presente, nunca nos $2 / 5$ anteriores .. 7

6. Pronoto sem impressão longitudinal discal mediana; freqüentemente com impressão transversal completa (Fig. 10a); cada élitro freqüentemente com uma carena sublateral (Fig. 10a) Neoelmis

Pronoto com impressão longitudinal discal mediana (Fig. 9a); impressão oblíqua de cada lado, completa ou incompleta, em forma de $\mathrm{U}$ nos $4 / 5$ posteriores (Fig. 9a); cada élitro com duas carenas sublaterais (Fig. 9a), raramente com uma; epipleura raramente tomentosa . Microcylloepus

7. Proepímero e proepisterno com uma faixa de tomento estendendo-se da coxa à margem lateral do pronoto (Fig. 6c); pronoto com uma impressão longitudinal, mas sem impressão transversal (Fig. 6a)

Hexacylloepus

Proepímero e proepisterno com ou sem tomento, mas, se presente, não alcançando a margem lateral do pronoto; pronoto sem impressão longitudinal, algumas vezes com impressão transversal . 8

8. Processo prosternal relativamente estreito entre as procoxas (Fig. 14b), largura nitidamente menor que a metade da largura da margem anterior do prosterno .9

Processo prosternal largo entre as coxas (Fig. 13b, 15b), igual ou maior que a metade da largura da margem anterior do prosterno

9. Ápice do processo prosternal arredondado (Fig. 14b); largura entre as coxas $1 / 4$ da largura da margem anterior do prosterno; pronoto com área sem granulação de tamanho variável em torno da linha média; sem carenas ou depressões (Fig. 14a)

Stenhelmoides

9'. Ápice do processo prosternal obliquamente truncado (Fig. $4 b$ ); largura entre as coxas aproximadamente $1 / 3 \mathrm{da}$ largura da margem anterior do prosterno; pronoto granuloso, com carenas sublaterais e duas carenas medianas longitudinais incompletas.(Fig. 4a) ......... .. Cylloepus

10. Pronoto apresentando protuberâncias ou gibosidades (Fig. 13a) Stegoelmis 
Pronoto sem protuberâncias ou gibosidades; carenas geralmente presentes

11. Pronoto com quatro carenas longitudinais formadas por pequenos tubérculos, sem impressão transversal (Fig. 15a); proepímero e proepisterno desprovidos de tomento (Fig. 15b) Xenelmis

Pronoto com duas carenas sublaterais (Fig. 5a), geralmente com impressão transversal na porção mediana; proepímero e proepisterno com tomento próximo à margem lateral (Fig. 5c)

Heterelmis

\section{LARVAS}

1. Corpo deprimido dorso-ventralmente com expansões laterais achatadas e armadas de cerdas (Figs. 7 d-e; 11c)

Corpo cilíndrico (Fig. 5d) ou subcilíndrico (Fig. 14e) (Elminae) ... 4

2. Corpo fortemente achatado dorso-ventralmente (Fig. 11c); pleura presente nos segmentos abdominais I-VIII (Fig. 11d) (Larainae) Phanocerus Corpo não fortemente achatado dorso-ventralmente (Fig. 7d); pleura presente nos segmentos abdominais I-VI (Fig. 7e; 14f) 3

3. Segmento abdominal VIII com um grande tubérculo dorsal em cada lado da linha mediana (Fig. 7d); expansões laterais dos segmentos largas, portando cerdas longas (Fig. 7d, e) (Larainae) Hexanchorus Segmento abdominal VIII sem tubérculos (Fig 14e); expansões laterais dos segmentos estreitas, portando uma fileira de cerdas curtas (Fig. 14f) (Elminae) .......

Xenelmis

4. Protórax com esterno posterior, cavidade procoxal fechada atrás (Fig. 5e) .

Protórax sem esterno posterior; cavidade procoxal aberta atrás (Fig. 6e)

5. Superfície dorsal, do mesonoto ao segmento abdominal VIII com tubérculos espatulados ou espinhos curtos arranjados em seis ou mais fileiras longitudinais ou diagonais distintas, meso- e metapleura divididas em dois ou três pleuritos (Fig. 5d)

Superfície dorsal, do mesonoto ao segmento abdominal VIII, com tubérculos dorsais, se presentes, nunca arranjados em fileiras distintas, oblíquas ou longitudinais além de um par dorsal de fileiras acompanhando a linha mediana; meso- e metapleura divididas em dois pleuritos (Figs. 6e, 9d) 7

6. Fileiras de tubérculos longitudinais ou diagonais em número de dez, do mesonoto ao segmento abdominal VIII (Fig. 5d); meso- e metapleura divididas em três partes (Figs. 5e, f) Heterelmis

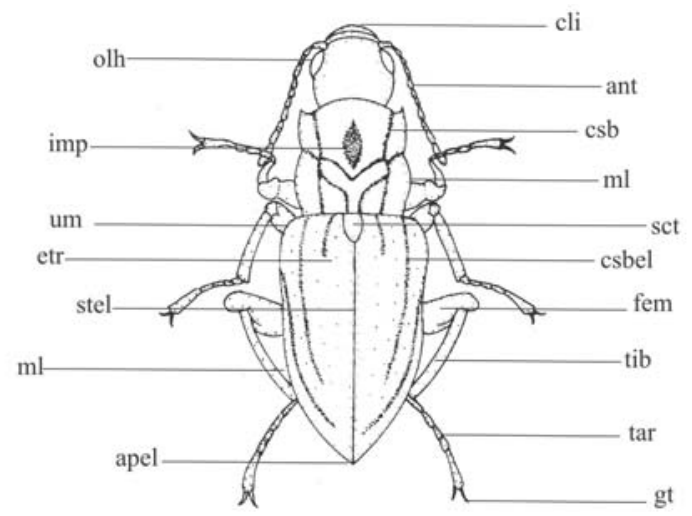

$1 \mathrm{a}$

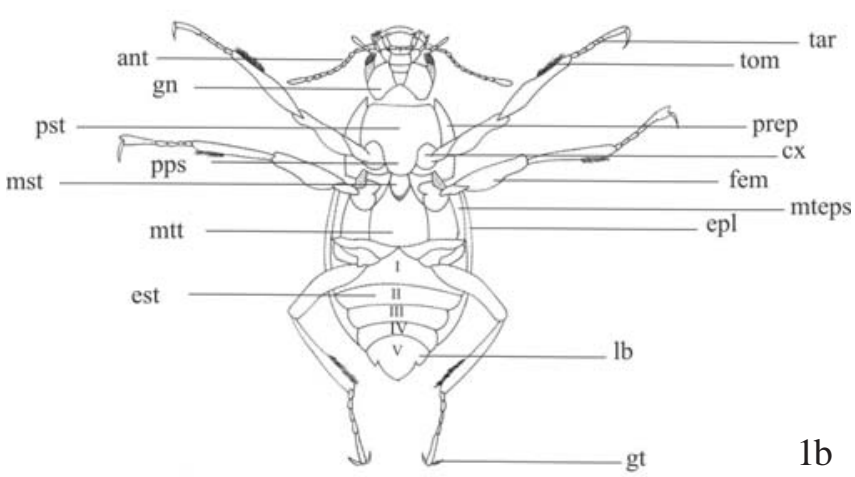

Fig. 1. Esquema de um Elmidae adulto do gênero Microcylloepus: a) vista dorsal; b) vista ventral. ant - antena, apel - ápice do élitro, casb carena sublateral, casbel - carena sublateral do élitro, cli - clípeo, cx coxa, epl - epipleura, espn - estria de puncturas, est - esternito abdominal, fem - fêmur, gn - gena, gt - garra tarsal, impl - impressão longitudinal, mgla - margem lateral, mst - mesosterno, mteps metaepisterno, mtt - metasterno, lb - lobo, ppp - processo prosternal, prep - proepímero, pst - prosterno, olh - olho composto, sct - escutelo, stel - sutura elitral, tar - tarso, tib - tíbia, tom - tomento, tr - trocanter, ts - tarsômeros, um - úmero. Escalas: 1,0 mm.

Fileiras de tubérculos longitudinais em número de seis no tórax e oito nos segmentos abdominais de I-VIII (Fig. 15a); meso- e metapleura divididas em duas partes (Figs. 15b)

Larva A

7. Dorso com tubérculos parcialmente arranjados em fileiras paralelas pelo menos em alguns segmentos (Fig. 9c) .. Microcylloepus

Dorso com ou sem tubérculos (Fig. 8c); se presentes, não arranjados em fileiras paralelas (Fig. 15a) .8

8. Cabeça com dente frontal distinto de cada lado, entre a antena e o clípeo (Fig. 8e)

9

Dentes frontais indistintos ou ausentes ....................... 10

9. Corpo hemicilíndrico; tubérculos arredondados; pronoto com projeções ântero-laterais pontiagudas, emarginando a cabeça (Fig. 8c) ................ Macrelmis

Corpo cilíndrico; tubérculos espatulados; pronoto sem projeções ântero-laterais pontiagudas (Fig. 16a) .........

Larva B. 


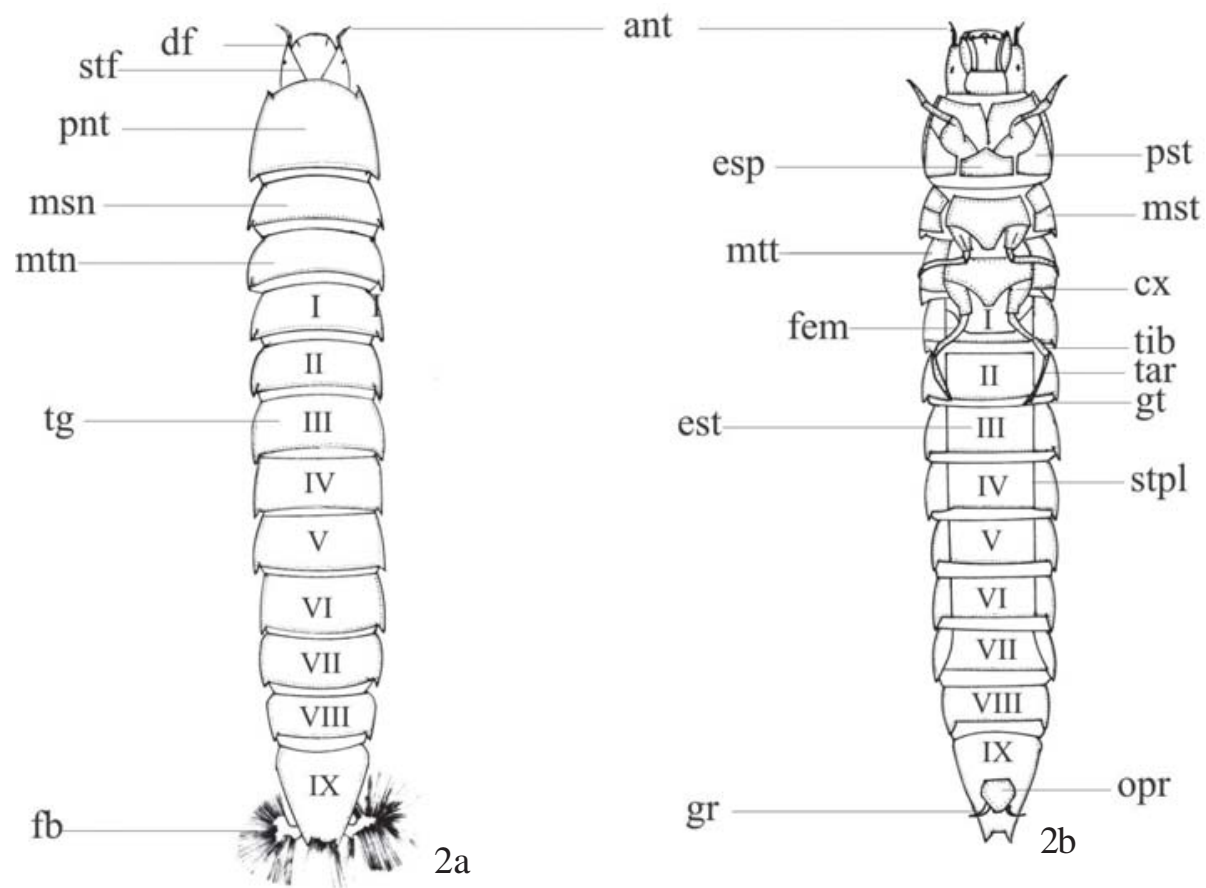

Fig. 2. Esquema de uma larva de Elmidae do gênero Macrelmis: a) vista dorsal, b) vista ventral. ant - antena, cx - coxa, df - dente frontal, esp esterno posterior; est - esternito III, fb - filamentos brânquias, fem - fêmur, gr - garra opercular, gt - garra tarsal, msn - mesonoto, msp mesosterno, mtn - metasterno, mtp - metasterno, opr - opérculo, pnt - pronoto, pst - prosterno, stf - sutura frontal, stpl - sutura pleural, tar tarso, teg - tergito III, tib - tíbia. Escalas: $1,0 \mathrm{~mm}$.

10. Tergitos abdominais com uma saliência (corcova) médiodorsal, em pelo menos quatro segmentos, algumas vezes, com saliências (corcovas) látero-dorsais. (Fig. $12 \mathrm{a}, \mathrm{b})$ Promoresia

Tergitos com ou sem tubérculos, mas sem saliências como acima 11

11. Linha médio-dorsal acompanhada de cada lado por uma fileira de tubérculos (Fig. 6d) Hexacylloepus

Dorso com tubérculos pequenos ou inconspícuos não formando fileiras ou elevações (Fig. 10c) 12

12. Pleura presente nos segmentos abdominais I-VII (Fig. 10d); segmento abdominal IX três vezes mais longo que largo; opérculo ocupando o terço posterior do segmento (Fig. 10d) Neoelmis

Pleura presente nos segmentos abdominais I-II (Fig. 17b); segmento abdominal IX duas vezes mais longo que largo, com uma carena médio-dorsal; opérculo um pouco menor que a metade do comprimento do segmento (Fig. 17b) Larva C

13. Pleura abdominal restrita ao primeiro segmento (Fig. 18b); esternos torácicos com tubérculos Larva D

Segmentos abdominais I-VII com pleura (Fig. 19b); esternos torácicos sem tubérculos Larva E

\section{BREVECARACTERIZAÇÃODOS GÊNEROS}

Larainae

Gênero Hexanchorus (Figs. 7a-e)

Adulto. Corpo pubescente, alongado, com lados subparalelos e moderadamente convexo dorsalmente. Cabeça parcialmente retraída no protórax, peças bucais visíveis. Pronoto largo no terço posterior, estreitando-se anteriormente; com uma profunda impressão transversa no terço anterior. Escutelo achatado, oval. Prosterno curto. Processo prosternal alongado, largo na base e com ápice agudo.

Larva. Corpo alongado, subcilíndrico, oval ou suboval em seção transversal; margens dos segmentos torácicos e abdominais moderadamente expandidas lateralmente. Superfície dorsal sem fileiras de tubérculos. Pro-, meso- e metanoto com ou sem uma gibosidade em cada lado adjacente à linha mediana. Cavidades procoxais abertas posteriormente. Abdome sem escleritos tergo-pleurais; tergitos I-VII com duas moderadas gibosidades póstero-medianas; tergito VIII com uma conspícua gibosidade em cada lado da linha mediana. Escleritos esterno-pleurais presentes nos segmentos I-VI.

Hábitat. Os exemplares desse gênero foram encontrados em substrato rochoso com ou sem hidrófitas e em folhiço retido em áreas de correnteza de rios e riachos em altitudes de 20 a $1900 \mathrm{~m}$.

Gênero Phanocerus (Fig. 11)

Adulto. Corpo pubescente com os lados subparalelos, moderadamente convexo dorsalmente. Pronoto alargado nos 

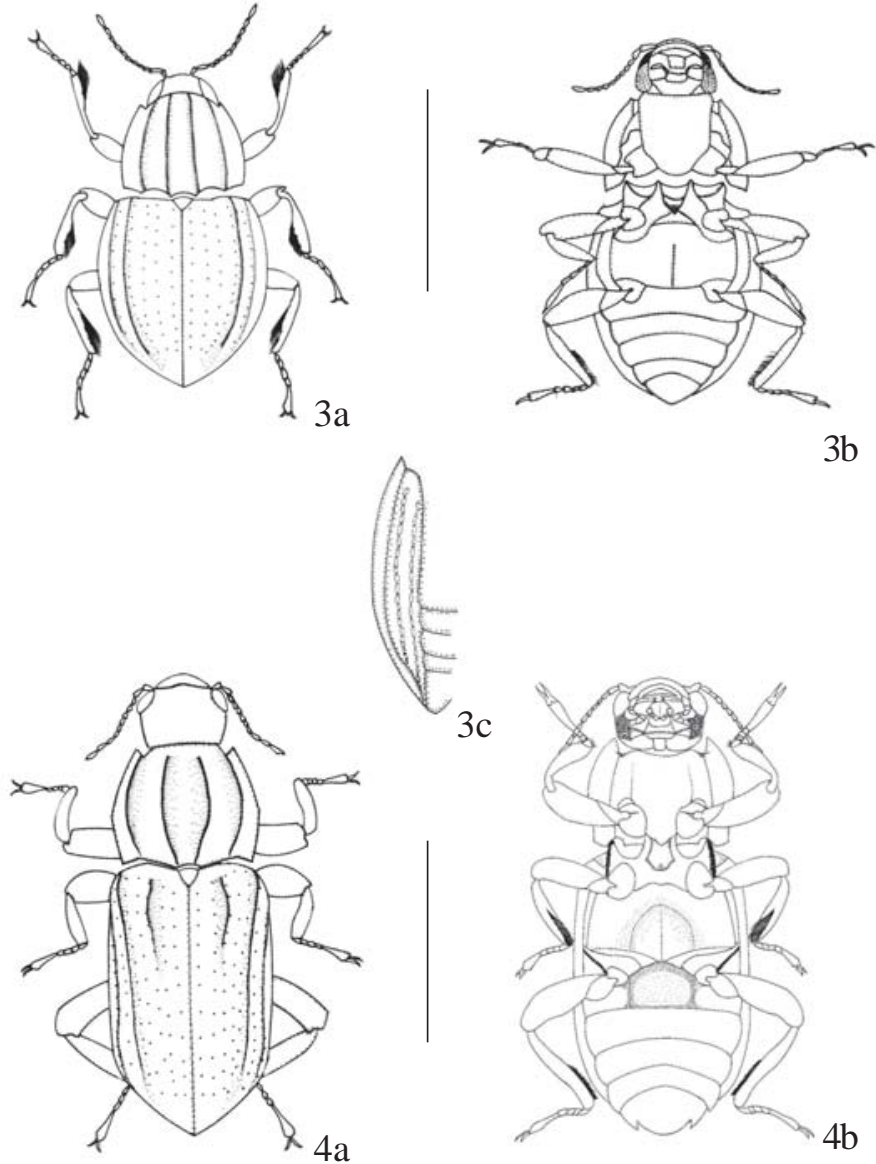

$3 b$

Figs. 3-4. 3, Austrolimnius sp. Adulto: a, vista dorsal; b, vista ventral; c, epipleura com fileira de grânulos; 4, Cylloepus sp. Adulto: a, vista dorsal; b, vista ventral. Escalas: $1,0 \mathrm{~mm}$.

2/5 posteriores; porção mediana com uma impressão longitudinal; porções póstero-laterais com uma protuberância delimitada por impressões e por uma profunda depressão anterior.

Larva. Corpo alongado, achatado, um pouco convexo dorsalmente, lados subparalelos; margens de todos os segmentos com expansões falciformes. Superfície dorsal sem fileiras de cerdas; tubérculos pouco desenvolvidos. Cavidade procoxal fechada posteriormente. Meso- e metapleura divididas em duas partes. Abdome sem escleritos tergopleurais; escleritos esterno-pleurais nos segmentos I - VIII; segmento IX com ápice arredondado ou moderadamente emarginado.

Hábitat. Os exemplares foram coletados predominantemente em folhiço, tanto retido em áreas de correnteza quanto depositado em remansos, mas também em substrato rochoso ou arenoso de rios e riachos em altitudes variando entre 20 e $1900 \mathrm{~m}$.

\section{Elminae}

Gênero Austrolimnius (Fig. 3)

Adulto. Corpo oval a subparalelo. Pronoto com a margem anterior moderadamente a fortemente arqueada; com uma carena sublateral em cada lado, que se estendem da margem posterior até próximo à margem anterior e pode ou não ser proeminente; disco com ou sem uma impressão longitudinal mediana. Élitro sem puncturas ou com uma distinta série de puncturas; com duas proeminentes carenas sublaterais. Epipleura com uma linha de grânulos, a qual nos 2/5 anteriores posiciona-se a meia distância das margens dorsal e ventral e nos $3 / 5$ posteriores aproxima-se da margem ventral. Prosterno muito longo à frente das coxas.

Hábitat. Os exemplares desse gênero foram coletados em substrato rochoso com ou sem hidrófitas e em folhiço retido em áreas de correnteza de rios e riachos entre 20 e 1900 m de altitude.

\section{Gênero Cylloepus (Fig. 4)}

Adulto. Corpo alongado, subparalelo. Proepímero e proepisterno sem tomento. Pronoto com uma carena longitudinal sublateral de cada lado, geralmente estendendose da região posterior para a região anterior; com uma impressão longitudinal no disco. Élitro estriado e com puncturas; sem estria acessória; com duas ou muito raramente
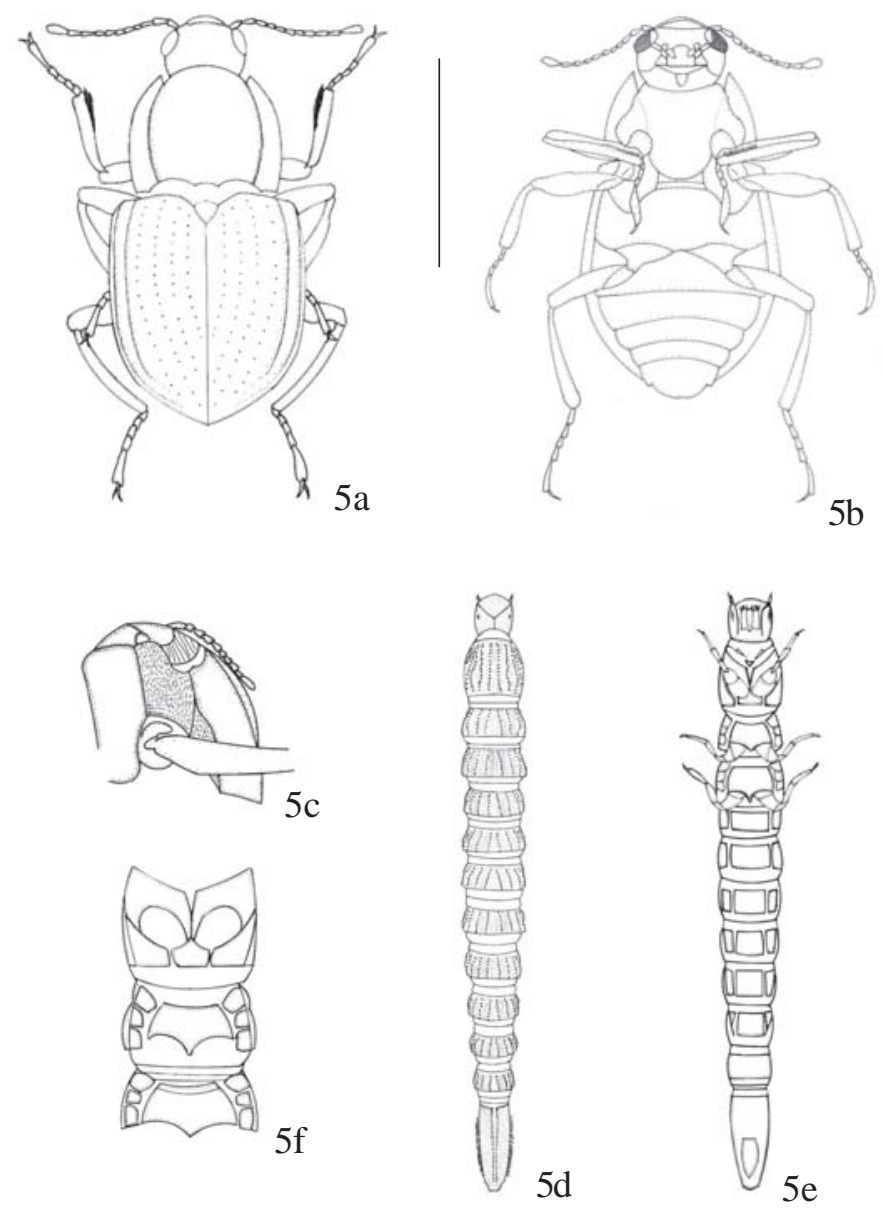

Fig. 5. Heterelmis sp. Adulto: a, vista dorsal; b, vista ventral; c, proepímero e proepisterno com tomento. Larva: d, vista dorsal; e, vista ventral; $\mathrm{f}$, tórax, vista ventral. Escalas: $1,0 \mathrm{~mm}$. 

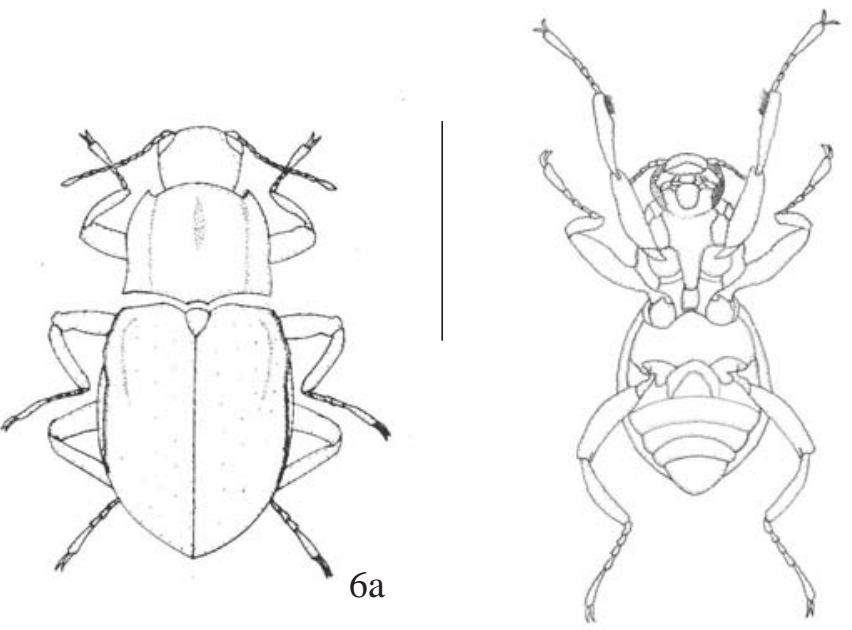

$6 \mathrm{~b}$
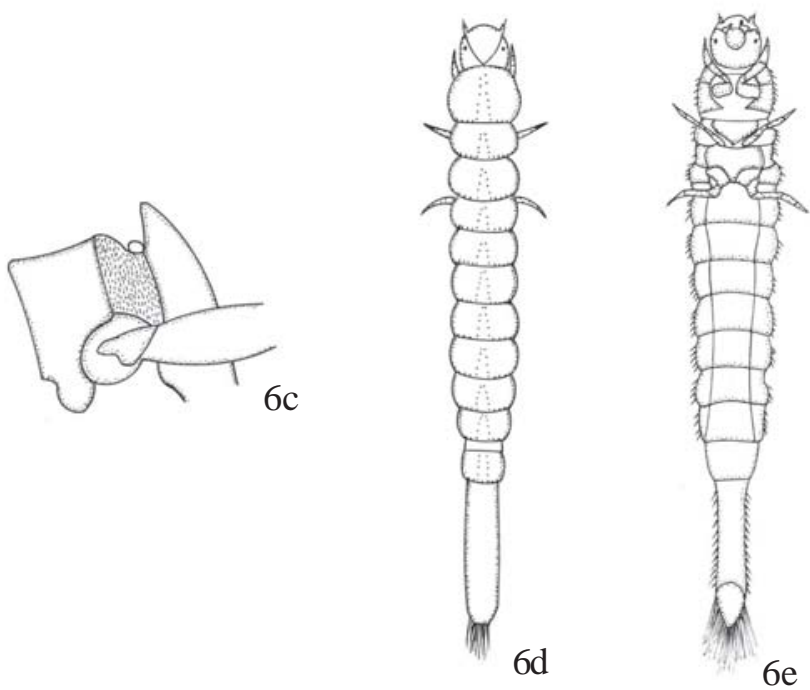

Fig. 6. Hexacylloepus sp. Adulto: a, vista dorsal; b, vista ventral; c, proepímero e proepisterno com tomento. Larva: d, vista dorsal; e, vista ventral. Escalas: $1,0 \mathrm{~mm}$.

uma carena sublateral. Prosterno muito longo à frente das coxas; processo prosternal longo, com margem posterior geralmente arredondada.

Hábitat. Os exemplares foram encontrados em substrato rochoso e folhiço retido em áreas de correnteza de rios e riachos em altitudes variando de 20 a 1900 m.

\section{Gênero Heterelmis (Fig. 5)}

Adulto. Corpo suboval a subparalelo. Pronoto com a margem anterior moderadamente arqueada; com uma carena sublateral que se estende da margem posterior até ou muito próximo à margem anterior; com ou sem impressão transversal mediana; com ou sem impressão longitudinal no disco; e com ou sem impressão oblíqua em cada lado na metade posterior. Élitro com uma carena longitudinal no sexto e no oitavo intervalos. Proepímero e proepisterno com tomento. Prosterno muito longo à frente das coxas anteriores; processo prosternal longo, muito largo, com a margem posterior larga de arredondada a truncada.
Larva. Corpo subparalelo, cilíndrico a subcilíndrico em seção transversal; superfície dorsal (exceto o tergito abdominal IX, que possui uma elevação longitudinal mediana) um pouco convexa e com fileiras paralelas ou fracamente oblíquas de tubérculos. Propleura dividida em duas partes, a parte anterior encontra a linha mediana do corpo, sendo o esterno completamente suprimido. Cavidade procoxal fechada. Mesoe metapleura divididas em três partes. Segmentos abdominais I - VII com pleura circundada pelas suturas tergo-pleural e esterno-pleural convergindo e encontrando-se próximo à margem posterior de cada segmento.

Hábitat. Os exemplares foram coletados em substrato rochoso e em folhiço retido em áreas de correnteza de rios e riachos a altitudes variando de 20 a 1900m.

\section{Gênero Hexacylloepus (Fig. 6)}

Adulto. Corpo alongado, subparalelo. Pronoto com uma carena sublateral longitudinal em cada lado, estendendo-se da região posterior para a região anterior; com uma impressão longitudinal no disco. Élitro estriado e punctuado; sem estria acessória; com duas carenas sublaterais em cada lado.
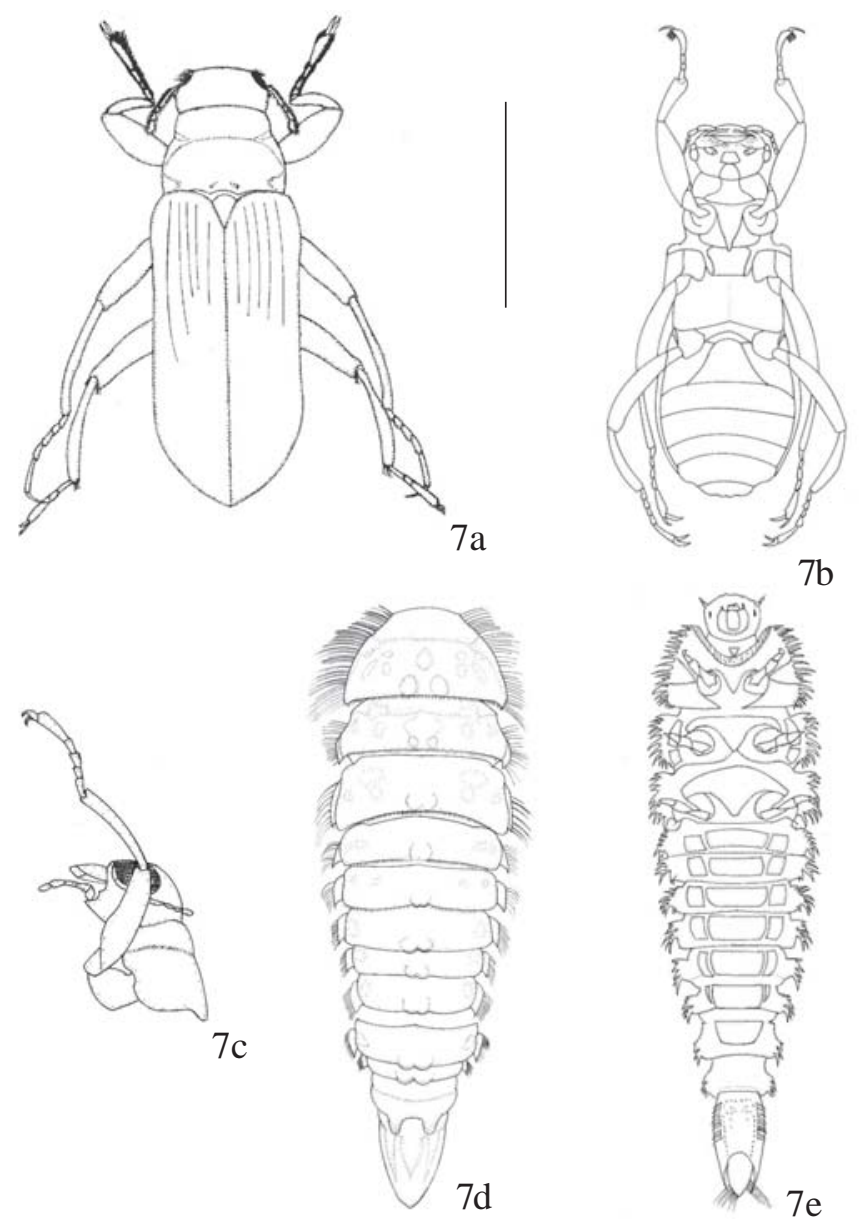

Fig. 7. Hexanchorus sp. Adulto: a, vista dorsal; b, vista ventral; c, cabeça e protórax, vista lateral. Larva: d, vista dorsal; e, vista ventral. Escalas: $1,0 \mathrm{~mm}$. 

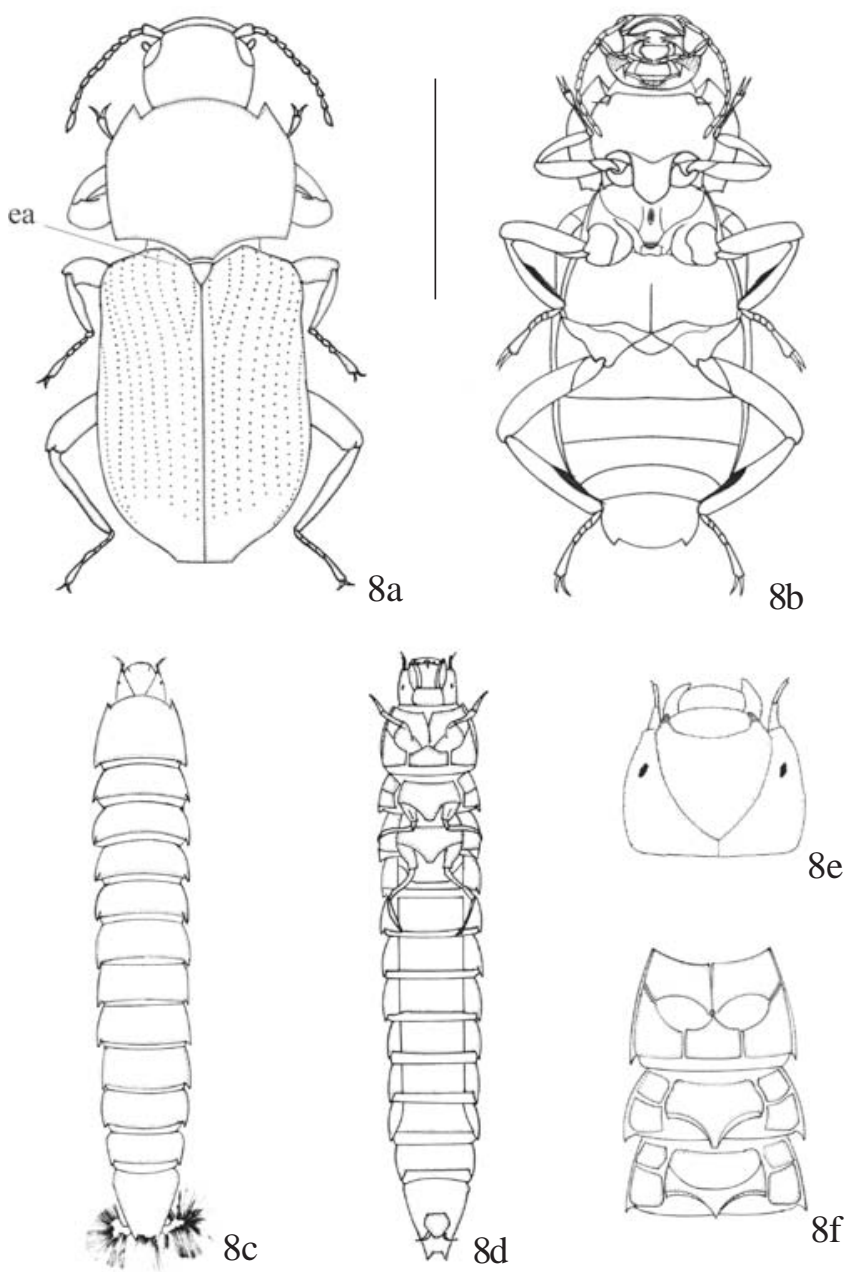

Fig. 8. Macrelmis sp. Adulto: a, vista dorsal; b, vista ventral. Larva: c, vista dorsal; d, vista ventral; e, cabeça, vista dorsal; f, tórax, vista ventral. ea - estria acessória. Escalas: 1,0 $\mathrm{mm}$.

Prosterno muito longo à frente das coxas. Mesosterno com uma profunda e moderadamente estreita depressão, onde se encaixa o processo prosternal. Metasterno com uma linha impressa longitudinal e mediana.

Larva. Corpo paralelo, hemicilíndrico. Margem posterior dos tergitos e esternitos e margem anterior do protórax emarginada por tubérculos portando tufos de cerdas. Margem anterior da cabeça com um indistinto dente entre a base da antena e o clípeo. Cavidade procoxal fechada e separada medianamente por um esclerito relativamente proeminente. Propleura não dividida; meso- e metapleura divididas em duas partes. Segmentos abdominais I - VII com pleura circundada pelas suturas tergo-pleural e esterno-pleural, as quais se encontram próximo à margem posterior dos segmentos. Opérculo mais curto que 1/3 do comprimento do segmento IX.

Hábitat. Os exemplares desse gênero foram coletados em substrato rochoso, folhiço retido em áreas de correnteza e em vegetação marginal de rios e riachos a altitudes entre 40 e 1600 m.
Gênero Macrelmis (Fig. 8)

Adulto. Corpo alongado, subparalelo. Pronoto com ou sem carena sublateral; se a carena estiver presente, pode ser completa ou evidente somente próximo à margem posterior; gibosidades ocasionalmente presentes em frente ao escutelo; disco com ou sem impressão longitudinal mediana. Élitro estriado e punctuado; com uma estria acessória em cada lado entre a sutura elitral e a segunda estria; sem carenas sublaterais. Prosterno muito longo à frente das coxas; processo prosternal longo e margem posterior amplamente arredondada.

Larva. Corpo achatado, paralelo, cilíndrico; com tubérculos pequenos e inconspícuos. Cabeça, quando observada dorsalmente, exposta e não escondida pelo pronoto; margem anterior em cada lado entre base da antena e o clípeo com um dente distinto. Pronoto emarginado. Cavidade procoxal aberta. Pro-, meso- e metapleura divididas em duas partes. Meso- e metasternos com ápice da projeção posterior truncada.; mesosterno, metasterno e o segmento abdominal I com uma impressão transversal nítida. Segmento abdominal I com uma carena muito marcada na forma de $\underline{\mathrm{W}}$. Segmentos abdominais I - VII com pleura circundada pelas suturas tergo-pleural e esterno-pleural, as quais se encontram próximo à margem posterior dos segmentos. Segmento abdominal IX duas vezes mais longo que largo. Opérculo menor que a metade do comprimento do segmento IX.
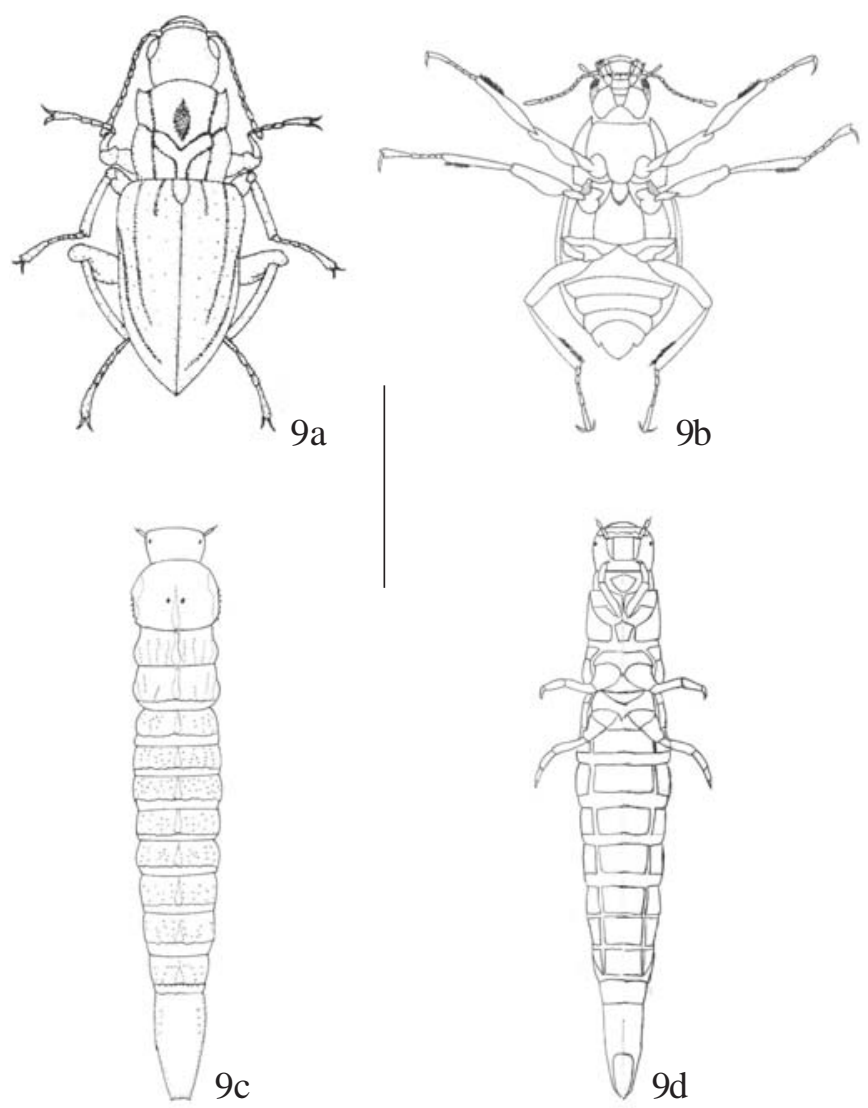

Fig. 9. Microcylloepus sp. Adulto: a, vista dorsal; b, vista ventral. Larva: c, vista dorsal; d, vista ventral. Escalas: 1,0 $\mathrm{mm}$. 

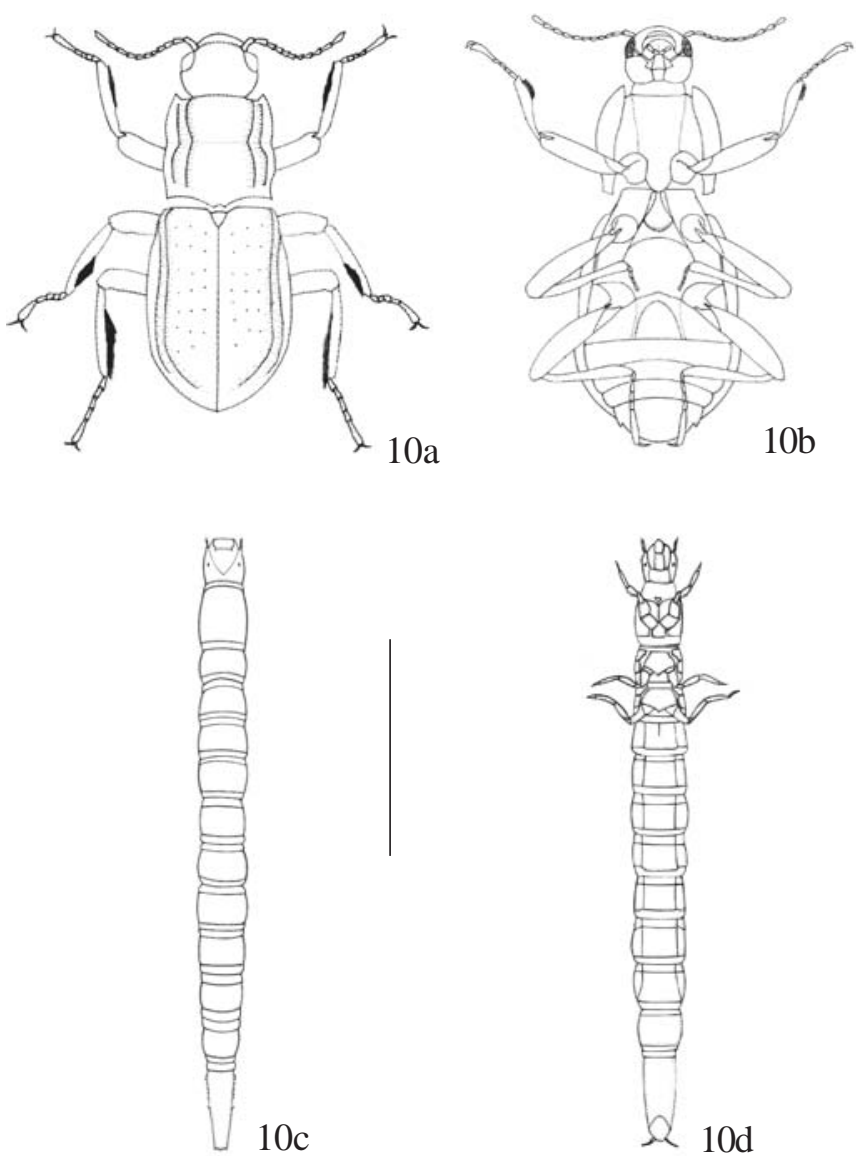

Fig. 10. Neoelmis sp. Adulto: a, vista dorsal; b, vista ventral. Larva: c, vista dorsal; d, vista ventral. Escalas: $1,0 \mathrm{~mm}$.

Hábitat. Os exemplares ocorrem predominantemente em folhiço, tanto retido em áreas de correnteza quanto depositado em áreas de remanso, mas também são encontrados em substratos rochosos, especialmente cascalho, ocorrendo em rios e riachos em altitudes entre 20 e $1900 \mathrm{~m}$.

Gênero Microcylloepus (Fig. 9)

Adulto. Corpo subparalelo. Pronoto em cada lado com uma carena sublateral que se estende da margem posterior até a margem anterior; com uma ampla e moderada impressão oblíqua de cada lado, completa ou incompleta, em forma de U iniciandose nos $2 / 5$ anteriores e ocupando os $4 / 5$ posteriores, a qual é sempre distinta nos lados, mas em algumas espécies não é evidente na região discal; disco com ou sem uma impressão longitudinal mediana ampla e profunda. Élitro punctuado e estriado; com uma carena sublateral no oitavo intervalo e às vezes uma no sexto. Prosterno muito longo à frente das coxas; processo prosternal longo, estreito a moderadamente estreito e com a margem posterior amplamente arredondada.

Larva. Corpo paralelo, cilíndrico e muito convexo ventralmente. Tubérculos da região mediana dos tergitos abdominais I-VIII arranjados, em sua maioria, em fileiras longitudinais paralelas. Cabeça sem dente distinto na margem anterior entre a base da antena e o clípeo. Cavidade procoxal fechada. Pro-, meso- e metapleura divididas em duas partes. Segmentos abdominais I - VII com pleura circundada pelas suturas tergo-pleural e esterno-pleural, as quais se encontram próximo à margem posterior dos segmentos.

Hábitat. Exemplares desse gênero foram coletados em substratos rochosos (lajes, calhaus e cascalho) com ou sem hidrófitas e em folhiço retido em áreas de correnteza de rios e riachos em altitudes entre 20 e $1550 \mathrm{~m}$.

\section{Gênero Neoelmis (Fig. 10)}

Adulto. Corpo subparalelo, geralmente longo e estreito. Pronoto com a margem anterior moderadamente arqueada; com uma carena sublateral em cada lado, a qual se estende da margem posterior até próximo da margem anterior; e uma profunda, ampla e completa impressão transversal nos $2 / 5$ anteriores. Élitro punctuado e estriado; com uma carena sublateral no sexto intervalo. Prosterno muito longo à frente das coxas; processo prosternal longo, estreito ou amplo e
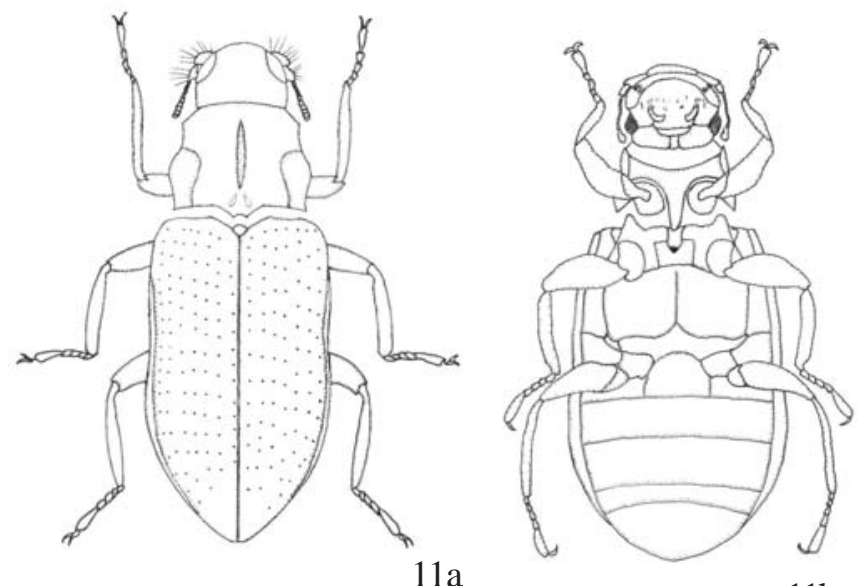

$11 b$
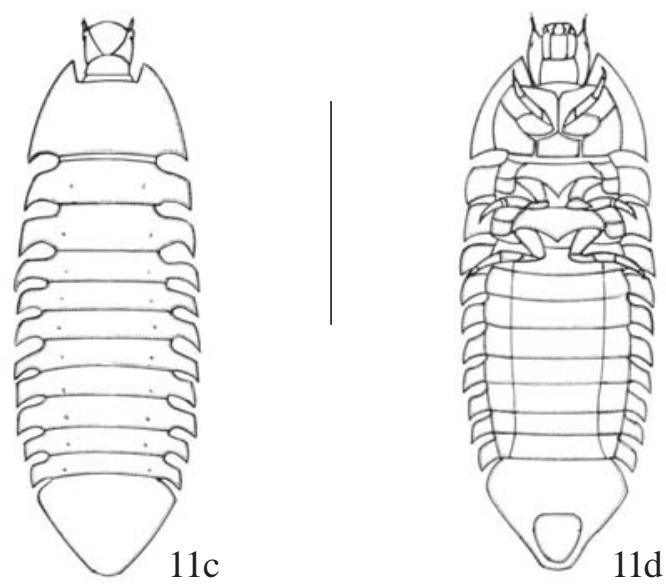

Fig. 11. Phanocerus sp. Adulto: a, vista dorsal; b, vista ventral. Larva: c, vista dorsal; d, vista ventral. Escalas: $1,0 \mathrm{~mm}$. 

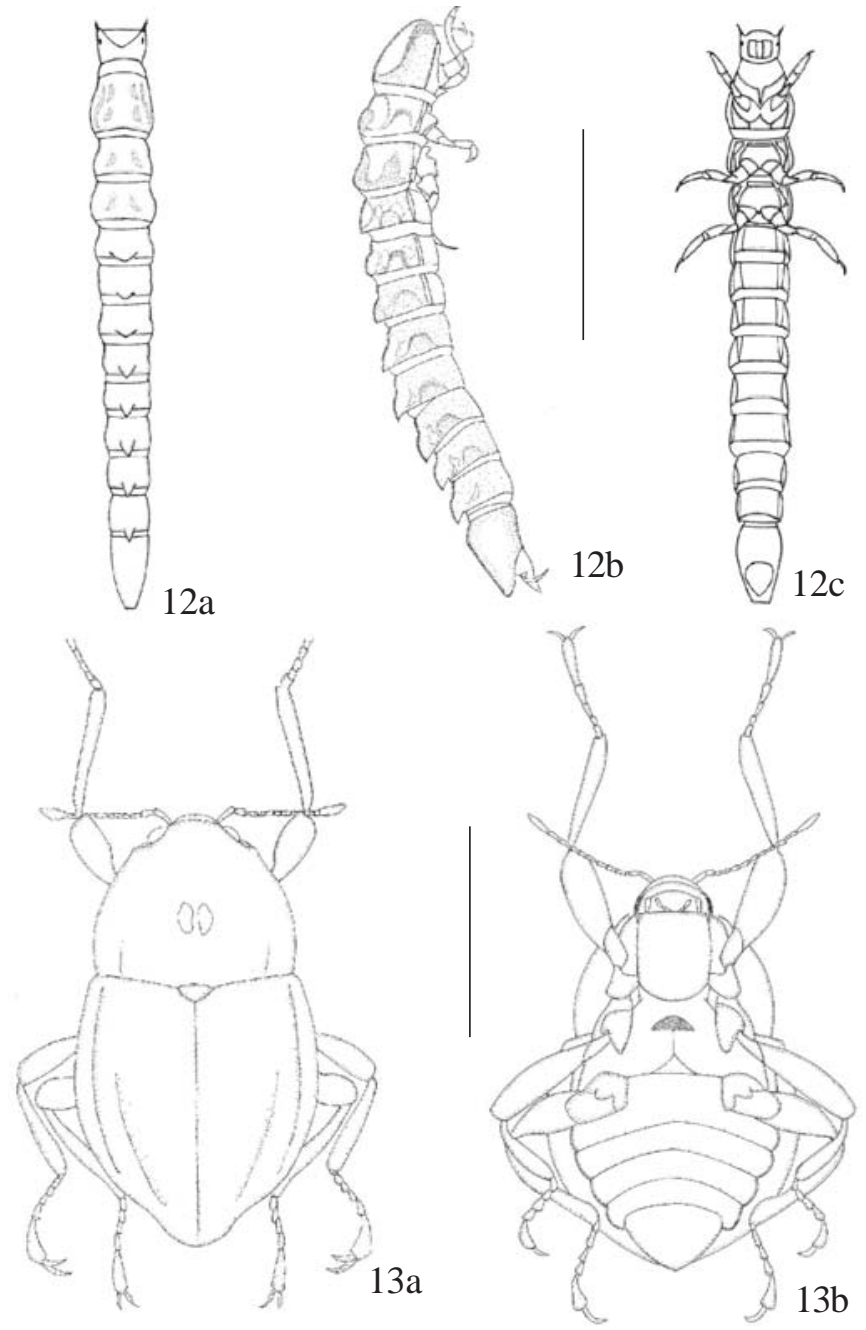

Figs. 12-13. 12 , Promoresia sp. Larva: a, vista dorsal; b, vista lateral; c, vista ventral; 13, Stegoelmis sp. Adulto: a, vista dorsal; b, vista ventral. Escalas: $1,0 \mathrm{~mm}$.

com margem posterior de aproximadamente truncada a amplamente arredondada.

Larva. Corpo subparalelo e cilíndrico a subtriangular em seção transversal; superfície dorsal bastante convexa. Margem anterior da cabeça entre a base da antena e o clípeo com um indistinto dente. Cavidade procoxal fechada. Pro-, meso- e metapleura divididas em duas partes. Segmentos abdominais I - VII com pleura.

Hábitat. Exemplares foram coletados em substrato rochoso (pedras e cascalho) com ou sem hidrófitas e em folhiço tanto em áreas de remanso quanto em áreas de correnteza de rios e riachos em altitudos entre 40 e $1900 \mathrm{~m}$.

\section{Gênero Promoresia (Fig. 12)}

Larva. Corpo subcilíndrico em seção transversal. Superfície dorsal com gibosidades visíveis a partir do segmento abdominal IV; com uma gibosidade no segmento abdominal IX e dilatação látero-posterior dos segmentos abdominais. Gibosidades indistintas nos segmentos abdominais I-III.
Cavidade procoxal fechada. Prosterno posterior com tubérculos. Pro, meso- e metapleura divididas em duas partes. Pleura presente nos segmentos abdominais I-IV, circundada pelas suturas tergo-pleural e esterno-pleural. Segmento abdominal IX com comprimento menor que três vezes a sua largura.

Hábitat. Exemplares desse gênero foram coletados em substrato rochoso e em folhiço depositado em remansos de rios e em altitudes de 20 a $1550 \mathrm{~m}$.

\section{Gênero Stegoelmis (Fig. 13)}

Adulto: Corpo oval, robusto, subparalelo. Pronoto com um leve sulco posterior próximo à margem lateral, com granulações ovais profundas e gibosidades no terço basal do pronoto. Élitro com estrias grosseiramente punctuadas, áreas do úmero e subapicais geralmente com gibosidades e protuberâncias. Processo prosternal largo, com ápice arredondado a truncado (Manzo 2005; Spangler 1990). Os exemplares observados para este estudo apresentam somente o par mediano de gibosidades do pronoto e élitros sem protuberância ou gibosidade nas áreas umeral e subapical, com duas carenas próximas aos intervalos 5 (quinto) e 6 (sexto). A carena próxima ao quinto intervalo começa aproximadamente na metade do élitro.

Hábitat: Exemplares de Stegoelmis foram coletados em folhiço retido em áreas de correnteza de riacho a aproximadamente $1000 \mathrm{~m}$ de altitude.

\section{Gênero Stenhelmoides (Fig. 14)}

Adulto. Corpo alongado, subparalelo. Pronoto sem carenas ou sulcos; com área de plastrão e uma área mediana sem plastrão. Élitro sem carenas, podendo apresentar linhas elevadas de pequenos grânulos da base ao ápice; com áreas estreitas ou largas de plastrão; sutura marginal sem plastrão; superfície granulosa com cerdas curtas e esparsas; fileiras de puncturas presentes ou não. Processo prosternal estreito. Metasterno com depressão longitudinal mediana.
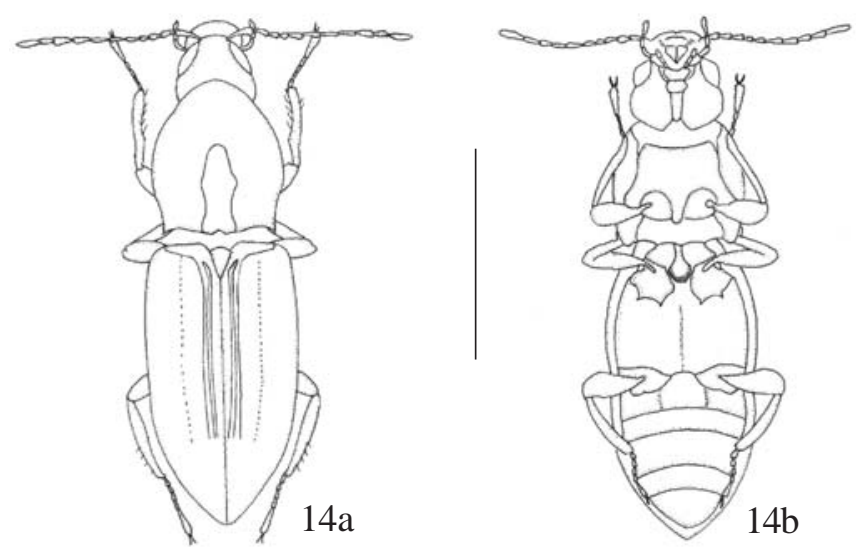

Fig. 14. Stenhelmoides sp. Adulto: a, vista dorsal; b, vista ventral. Escalas: 1,0 $\mathrm{mm}$. 

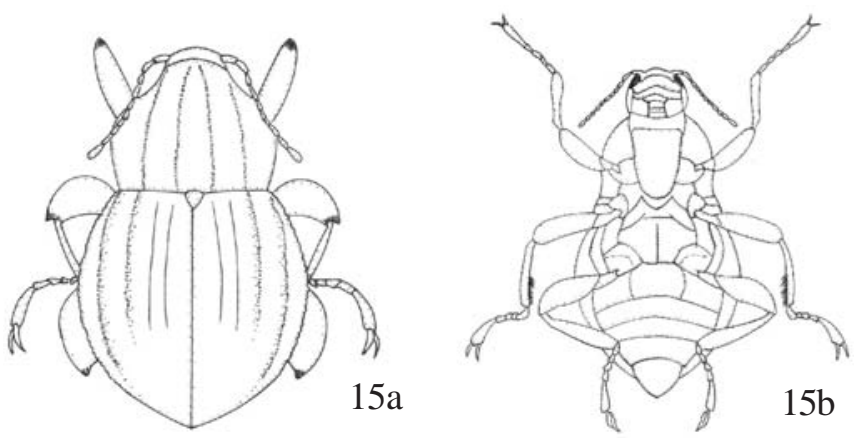
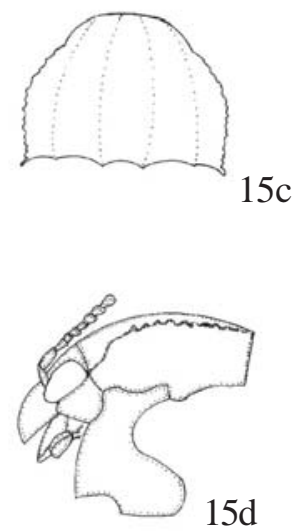

$5 \mathrm{c}$

$5 d$
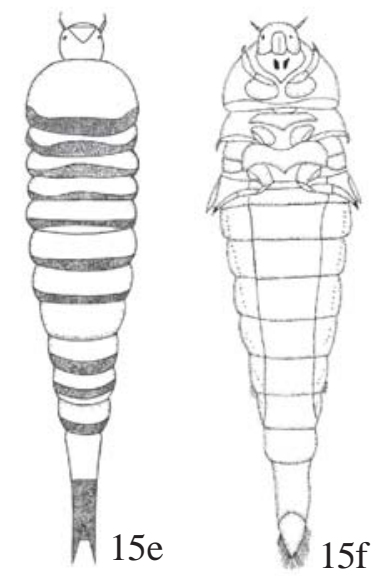

Fig. 15. Xenelmis sp. Adulto: a, vista dorsal; b, vista ventral; c, cabeça e protórax, vista lateral; d, pronoto. Larva: e, vista dorsal; f, vista ventral. Escalas: 1,0 $\mathrm{mm}$.

Hábitat. Exemplares encontrados em substrato arenoso em rio de baixada no município de Macaé.

Gênero Xenelmis (Fig. 15)

Adulto. Corpo fortemente ovalado. Pronoto com uma proeminente carena sublateral e disco sem impressão longitudinal mediana. Élitro punctuado e estriado; com duas carenas sublaterais formadas por fileiras de grânulos. Prosterno moderadamente curto à frente das coxas; processo prosternal longo e muito largo.

Larva. Corpo convexo, moderadamente deprimido dorsoventralmente, com tórax longo e abdome afilando-se posteriormente; margens dos segmentos expandidas e armadas de curtas cerdas; dorso com tubérculos pequenos não arranjados em fileiras. Cabeça sem dente na margem anterior entre a base da antena e o clípeo. Cavidade procoxal aberta posteriormente. Pro-, meso- e metapleura divididas em duas partes. Segmentos abdominais I - VI com pleura circundada pelas suturas tergo-pleural e esterno-pleural. Segmento abdominal IX três vezes mais longo que largo. Opérculo ocupando 2/5 do comprimento do segmento abdominal IX.

Hábitat. Exemplares desse gênero foram coletados em substrato rochoso (pedras e seixos) e em folhiço retido em áreas de correnteza de rios e riachos em altitudes variando entre 40 e $1550 \mathrm{~m}$.
Morfotipos não identificados.

Larva A (Fig. 16)

Corpo subcilíndrico. Cabeça mais estreita que o tórax; com cerdas e tubérculos; sem dente frontal entre o clípeo e antena. Pronoto com tubérculos; depressões e carenas oblíquas; meso- e metanoto com seis fileiras de tubérculos sobre as carenas longitudinais; tergitos abdominais com oito carenas de tubérculos. Prosterno posterior presente. Pro-, meso- e metapleura divididas em duas partes. Segmento abdominal I com esterno apresentando carena ou elevação em forma de W. Pleura abdominal presente nos segmentos I-VIII; tubérculos presentes na pleura nos segmentos abdominais IVII. Segmento abdominal IX com duas carenas laterais e uma mediana (com tubérculos); duas vezes mais longo que largo, opérculo comprimido no terço posterior.

Hábitat. Exemplares foram encontrados em substrato rochoso com ou sem hidrófitas, substrato arenoso e em folhiço retido em áreas de correnteza de rios e riachos em altitudes variando entre 90 e $1600 \mathrm{~m}$.
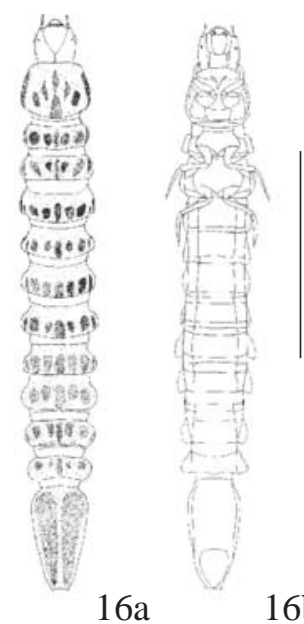

$16 b$

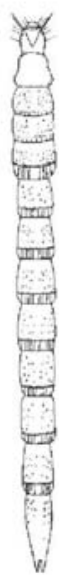

$18 \mathrm{~b}$

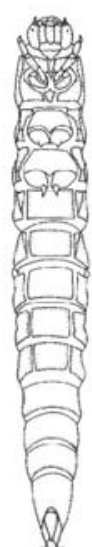

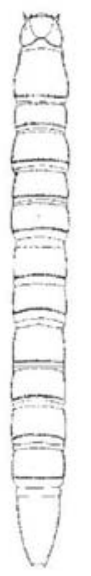

$17 \mathrm{a}$

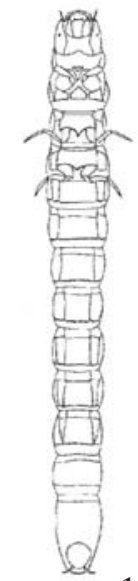

$17 \mathrm{~b}$

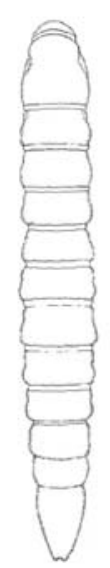

$18 \mathrm{a}$

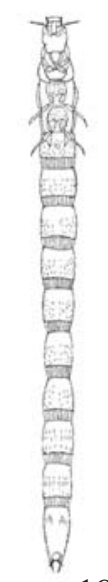

$19 \mathrm{a}$

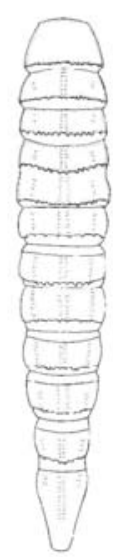

$20 \mathrm{a}$

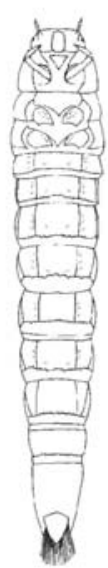

$20 b$
Figs. 16-20. 16, Elmidae larva A: a, vista dorsal; b, vista ventral; 17, Elmidae larva B: a, vista dorsal; b, vista ventral; 18, Elmidae larva C: a, vista dorsal; b, vista ventral; 19, Elmidae larva D: a, vista dorsal; b, vista ventral; 20, Elmidae larva E: a, vista dorsal; b, vista ventral. Escalas: $1,0 \mathrm{~mm}$ 
Larva B (Fig. 17)

Corpo cilíndrico; superfície dorsal sem elevações ou sulcos; segmentos abdominais com tubérculos dorsais. Cabeça sem dente frontal conspícuo entre o clípeo e a antena. Pronoto não emarginado. Cavidade procoxal aberta. Pro-, meso- e metapleura divididas em duas partes. Pleura nos segmentos abdominais I - VII. Um par de cerdas finas e longas dorsalmente em cada segmento abdominal. Esternitos pontiagudos, esternito abdominal I liso e menos sulcado. Segmento abdominal IX duas vezes mais longo que largo. Opérculo ocupando $2 / 5$ do comprimento do segmento IX, com ápice arredondado.

Hábitat. O material foi coletado em folhiço retido em áreas de correnteza de riachos em altitudes variando entre 100 e $1900 \mathrm{~m}$.

\section{Larva C (Fig. 18)}

Corpo cilíndrico, com tubérculos uniformemente distribuídos, não formando fileiras. Cabeça sem dente frontal entre o clípeo e a antena. Pro-, meso- e metanoto com depressões e fracas gibosidades laterais. Cavidade procoxal fechada; esterno posterior alto com carena transversal; pro-, meso- e metapleura divididas em duas partes. Pleura abdominal presente nos segmentos abdominais I-II. Segmento abdominal IX aproximadamente duas vezes mais longo que largo, com elevação médio-dorsal. Opérculo menor que a metade do comprimento do segmento IX, côncavo na região ventral, ápice agudo. Esta larva assemelha-se, no padrão geral à de Promoresia, mas sem as gibosidades dorsais desenvolvidas.

Hábitat. O material foi coletado em substrato rochoso com ou sem hidrófitas e em folhiço tanto em área de correnteza quanto em remanso de rios e riachos entre 90 e $1300 \mathrm{~m}$ de altitude.

\section{Larva D (Fig. 19)}

Corpo cilíndrico e longo, afilando para região posterior; com tubérculos não arrumados em fileiras. Cabeça sem dente frontal entre a antena e o clípeo. Cavidade procoxal aberta, sem esterno posterior. Pronoto sem tubérculos na região discal, com tubérculos nas laterais; meso- e metanoto com tubérculos espatulados e arredondados. Pro-, meso- e metapleura divididas em duas partes. Placas esternais reduzidas entre e adiante das coxas. Pleura somente no segmento abdominal I. Segmento abdominal IX com um par de dentes terminais curtos; ápice sinuoso. Segmento abdominal IX três vezes mais longo que largo; opérculo ocupando o terço posterior. Em formas menores há tubérculos no esterno, nas coxas e no mesonoto; segmentos abdominais com cerdas curtas e grossas presentes formando fileiras transversais; segmento abdominal IX com os dentes terminais mais longos e duas vezes mais longo que largo; opérculo ocupando o quarto posterior. Essa larva pode pertencer ao gênero Stenhelmoides cujas formas imaturas ainda não são conhecidas. No trecho potamal do Rio Macaé, onde o material aqui representado foi coletado, somente foram registrados adultos desse gênero.

Hábitat. Material encontrado em vegetação marginal e em substrato arenoso em um rio de baixada no município de Macaé.

\section{Larva E (Fig. 20)}

Corpo subcilíndrico. Cabeça sem dente frontal entre o clípeo e a antena. Pronoto sem fileiras de tubérculos, com depressões oblíquas laterais; meso- e metanoto com duas fileiras de tubérculos acompanhando a linha mediana e duas fileiras de tubérculos na região lateral. Dorso dos segmentos abdominais com duas fileiras de tubérculos acompanhando a linha mediana e quatro fileiras de tubérculos na região lateral. Pro-, meso- e metapleura divididas em duas partes. Segmentos abdominais de I-VII com pleura. Segmento abdominal IX aproximadamente três vezes mais longo que largo, com carena longitudinal e duas fileiras de tubérculos laterais. Opérculo ocupando o terço posterior do nono segmento.

Hábitat. Material encontrado em substrato rochoso de riacho a $100 \mathrm{~m}$ de altitude no município de Guapimirim.

Agradecimentos. Ao Laboratório de Entomologia, Departamento de Zoologia, Instituto de Biologia da Universidade Federal do Rio de Janeiro e ao Laboratório de Avaliação e Promoção da Saúde Ambiental, Fundação Oswaldo Cruz, Instituto Oswaldo Cruz, pelo acesso ao material para confecção da chave. Ao CNPq pelo apoio financeiro.

\section{REFERÊNCIAS}

Bachmann, A. O. (1977). Cyphonidae, Psephenidae, Byrrichidae, Limnichidae, Dryopidae, Elminthidae y Heteroceridae, p. 238 244. In: Hurlbert, S. H (ed.). Biota Acuática de Sudamérica Austral. San Diego State University, San Diego, xiv+342 p.

Blackwelder, R. E. (1944). Checklist of the Coleopterous insects of Mexico, Central America, The west Indies, and South America. Pat 2. Bulletin of the United States Natural Museum 185: 189341.

Brown, H. P. 1972. Aquatic dryopoid beetles (Coleoptera) of United States. Biota of Freshwater ecosystem, identification manual no 6. U.S. Environmental Protection Angency, Ohio, 82 p.

Brown, H. P. 1981. A distribution survey of the word genera of aquatic dryopoid beetles (Coleoptera: Dryopidae, Elmidae, and Psephenidae Sen. Lat.). The Pan-Pacific Entomologist 57: 133-148.

Brown, H. P. 1987. Biology of riffle beetles. Annual Review of Entomology 32: 253-273.

Hinton, H. E. 1936. Descriptions and figures of new Brazilian Dryopidae (Coleoptera). Entomologist 69: 283-289.

Hinton, H. E. 1937a. Descriptions and figures of Peruvian Dryopidae (Coleoptera). Entomologist 70: 131-138.

Hinton, H. E. 1937b. New species of Cylloepus from Brazil (Coleoptera, Dryopidae). Entomologist 70: 279-284.

Hinton, H. E. 1937c. Descriptions of new Brazilian Dryopidae and distributional records of others. Entomologist's Monthly Magazine 73: $6-12$.

Hinton, H. E. 1940a. A synopsis of the Brazilian species of Neoelmis Musgrave (Coleoptera, Elmidae). Annals and Magazine of Natural History 5: 129-153.

Hinton, H. E. 1940b. On some new Brazilian Microcylloepus, with a key to the species (Coleoptera, Elmidae). Annals and Magazine of Natural History 6: 236-248.

Hinton, H. E. 1940c. A synopsis of the Bolivian species of Cylloepus Er. (Coleoptera-Elmidae). Annals and Magazine of Natural History 6: 393-409.

Hinton, H. E. 1940d. A synopsis of the Brazilian species of Microcylloepus (Coleoptera-Elmidae). Entomologist's Monthly Magazine 76: 61-68. 
Hinton, H. E. 1945a. Stethelmis chilensis, new genus and species of Elmidae from Chile (Coleoptera). Proceedings of the Royal Entomological Society of London 14: 73-76.

Hinton, H. E. 1945b. A synopsis of Brazilian species of Cylloepus Er. (Coleoptera, Elmidae). Annals and Magazine of Natural History 12: 43-67.

Hinton, H. E. 1946a. A synopsis of the Peruvian species of Cylloepus Er. (Coleoptera, Elmidae). Annals and Magazine of Natural History 12: 713-733.

Hinton, H. E. 1946b. A synopsis of Brazilian species of Elsianus Sharp (Coleoptera, Elmidae). Transactions of the Royal Entomological Society of London 96: 125-149.

Hinton, H. E. 1951. A new Cylloepus from Argentina (Coleoptera, Elmidae). Annals and Magazine of Natural History 4: 820823.

Hinton, H. E. 1970. The zoological results of Gy Topál's collectings in South Argentina. 21. A second species of Stethelmis (Coleoptera, Elminthidae). Acta Zoologica Academiae Scientiarum Hungaricae 16: 109-113.

Hinton, H. E. 1972a. New species of Neoelmis from South America (Coleoptera, Elmidae). Papeis Avulsos Zool.(São Paulo) 26: 117-135.

Hinton, H. E. 1972b. The Venezuelan species of Neoelmis (Coleoptera: Elmidae). Journal of Entomology (B) 41: 133-144.

Hinton, H. E. 1972c. Two new genera of South American Elmidae (Coleoptera). The Coleopterist's Bulletin 26: 37-41.

Hinton, H. E. 1973a. New genera and species of Bolivian Elmidae (Coleoptera). The Coleopterist's Bulletin 27: 1-6.

Hinton, H. E. 1973b. The Venezuelan species of Hexacylloepus (Col., Elmidae). Entomologist's Monthly Magazine 108: 251-256.

Junk, W. \& Schenkling, S. 1910. Coleopterum Catalogus. pars 17: Dryopidae, Cyathoceridae, Georysiidae, Heteroceridae. W. Junk, Berlin. 1-47.

Junk, W. \& S. Schenkling. 1914. Coleopterum Catalogus. pars 58: Dascillidae, Helodidae, Eucinetidae. W. Junk, Berlin. 3-20.
Manzo, V. 2005. Key to the South America genera of Elmidae (Insecta: Coleoptera) with distributional data. Studies on Neotropical Fauna and Environment 40: 201-208.

Passos, M. I. S. \& M. Felix. 2004. A new species of Macrelmis Motschulsky from Southeastern Brazil (Coleoptera: Elmidae: Elminae). Studies on Neotropical Fauna and Environment 39: $49-51$.

Passos, M. I. S. \& M. Felix. 2004. Description of new species of Cylloepus Erichson from southeastern Brazil (Coleoptera: Elmidae). Revista Brasileira de Entomologia 48: 181-183.

Perkins, P. D. \& W. E. Steiner. 1981.Two new Peruvian species of the riffle beetles genus Xenelmis (Coleoptera: Elmidae). The PanPacific Entomologist 57: 306-312.

Spangler, P. J. 1980. A new species of the riffle beetle genus Portelmis from Ecuador (Coleoptera: Elmidae). Proceedings of the Entomological Society of Washington 82: 63-68.

Spangler, P. J. 1981. Pagelmis amazonica, a new genus and species of water beetles from Ecuador (Coleoptera, Elmidae). The PanPacific Entomologist 57: 286-294.

Spangler, P. J. 1989. A revision of the Neotropical aquatic beetles genus Stenhelmoides (Coleoptera: Elmidae). Smithsonian Contribution to Zoology 479: 63p

Spangler, P. J. 1990. A revision of the Neotropical aquatic beetles genus Stegoelmis (Coleoptera: Elmidae). Smithsonian Contributions to Zoology 502 (i-iv). 52p

Spangler, P. J. \& S. Santiago-Fragoso. 1989. A revision of the Neotropical aquatic beetles genera Disersus, Pseudodisersus, and Potamophilops (Coleoptera: Elmidae). Smithsonian Contribution to Zoology 446: $40 \mathrm{p}$

White, D. S. \& W. U. Brigham. 1996. Aquatic Coleoptera, p. 399-473. In: Merrit, R. W. \& K. W. Cummins. (eds). An Introduction to the Aquatic Insects of North America. 3 th edition., Kendall/ Hunt Publishing Company, Dubuquer, Iowa, xiii+862 p. 